\title{
Constructing Culture in Cowbirds (Molothrus ater)
}

\author{
David J. White \\ University of Pennsylvania
}

\author{
Julie Gros-Louis, Andrew P. King, \\ Maral A. Papakhian, and Meredith J. West \\ Indiana University Bloomington
}

\begin{abstract}
In past work, the authors produced divergent patterns of courtship and communication in juvenile male cowbirds (Molothrus ater) by providing them with different social experiences during their 1st year. Here the authors determined whether these different social patterns could be transmitted to new generations of juvenile males. In Experiment 1, the authors exposed groups of juveniles to adult males who differed in the amount of male-male competition they produced. In Experiment 2, they gave groups of juveniles either social access to adult males or only visual and acoustic access to those males. In both experiments, juvenile males developed patterns of courtship and competition similar to those expressed by the adult males with whom they had social contact. The juveniles never had the opportunity to observe some of the adults' behaviors that they came to replicate. This suggests that the role of the adults was to establish the social structure in the groups, modifying juveniles' early social interactions. Juveniles were then "cultured" within these different learning environments, constructing social behavior similar to the adult males' behavior in their 1st year.
\end{abstract}

Keywords: cowbirds, cultural transmission, communication

Typically, pronounced and enduring variation in behavior is accounted for by selection favoring different strategies in different environments (Foster \& Endler, 1999). In many instances, however, persistent behavioral differences across populations or subspecies need not be caused or maintained by genetic differences but can result from plasticity in developmental systems that responds to ecological conditions (Michel \& Moore, 1999; Schlichting \& Smith, 2002). Thus to understand how adaptive behavioral repertoires develop, it is necessary to understand what ecological factors structure plasticity in nature (West, King, \& White, 2003). For many species, the social environment can be a reliable structuring aspect of ecology.

Social experiences during development can play a role in influencing behavior, morphology, and even evolution (Gottlieb, 1999; West-Eberhard, 2003). Interactions with others early in life can affect brain development and stress responses (Champagne \& Curley, 2005; Francis, Diorio, Liu, \& Meaney, 1999) and can produce behavioral changes that can persist through lifetimes and

David J. White, Department of Psychology, University of Pennsylvania; Julie Gros-Louis, Andrew P. King, Maral A. Papakhian, and Meredith J. West, Department of Psychology, Indiana University Bloomington.

This work was supported by a National Science Foundation operating grant to Meredith J. West and Andrew P. King. Julie Gros-Louis received support from an Indiana University Developmental Training Group postdoctoral fellowship. David J. White received support from a National Sciences and Engineering Research Council postdoctoral fellowship. Gordon Burghardt and Todd Freeberg provided valuable comments on the manuscript. All work conformed to the Animal Behavior Society (1997) guidelines for ethical treatment of animals and was completed under Indiana University Animal Use and Care Study \#01-085.

Correspondence concerning this article should be addressed to David J. White, Department of Psychology, University of Pennsylvania, 3720 Walnut Street, Philadelphia, PA 19104. E-mail: whitedj@psych.upenn.edu be passed across generations (Denenberg \& Rosenberg, 1967). If social experiences can vary the development of traits important for reproduction, then early social experiences can potentially modify selection pressures (West et al., 2003).

When we manipulated the social environment for brown-headed cowbirds, we discovered pronounced plasticity in the development of mating behaviors. For example, by manipulating age-class composition of captive cowbird flocks, we have been able to produce (within a single generation) divergent patterns of social behavior in a local population of a magnitude comparable with some of the differences seen across subspecies (Freeberg, 1996; White, King, \& West, 2002). Allowing juvenile males either to interact or not to interact with adult males during their 1st year influenced the juveniles' vocal and social behavior (White, King, Cole, \& West, 2002; White, King, \& West, 2002). Juvenile males housed for their 1st year with adult males (referred to as the juvenile-adult, or JA, condition) developed aggressive, competitive breeding behavior. They engaged in male-male singing interactions, and they sang to and copulated with females monogamously. In contrast, juvenile males that were raised in social groups without adult males (juvenile, or J, condition) were less aggressive and copulated promiscuously. Notably, however, compared with JA-condition juveniles, J-condition juveniles developed breeding season courtship song that was more effective at eliciting females' copulatory responses (see Table 1 for a summary of differences between the two groups of juvenile males in White, King, \& West, 2002).

The mechanism of effect in the White, King, and West (2002) study was unclear. There were a multitude of factors that could have contributed to the observed effects. It was possible that the differences in juvenile behavior could be explained by copying or imitation; juveniles may have copied the songs or the singing patterns of adults, and this could have led to the emergence of other differences in behavior as a byproduct. On the basis of our 
Table 1

Patterns of Behavior Across Studies and Experiments

\begin{tabular}{|c|c|c|c|c|c|c|}
\hline \multirow[b]{2}{*}{ Behavior } & \multicolumn{2}{|c|}{$\begin{array}{l}\text { White, King, and } \\
\text { West (2002) }\end{array}$} & \multicolumn{2}{|c|}{ Experiment 1} & \multicolumn{2}{|c|}{ Experiment 2} \\
\hline & JA juvs & J juvs & HiCS juvs & LoCS juvs & $\mathrm{S}$ juvs & O juvs \\
\hline \multicolumn{7}{|l|}{ Prebreeding } \\
\hline CS & + & - & + & - & + & - \\
\hline Nn males & + & - & + & - & + & - \\
\hline Departures & - & + & - & + & - & + \\
\hline \multicolumn{7}{|l|}{ Breeding } \\
\hline $\mathrm{CS}$ & + & - & + & - & + & - \\
\hline Nn males & + & - & + & - & + & - \\
\hline Departures & - & + & - & + & - & + \\
\hline Fights & + & - & + & - & + & - \\
\hline Cops & $=$ & $=$ & $=$ & $=$ & $=$ & $=$ \\
\hline Pot & - & + & - & + & - & + \\
\hline Usurps & 0 & + & 0 & + & 0 & 0 \\
\hline Mating & monog & promis & monog & promis & monog & monog \\
\hline
\end{tabular}

Note. Summary of juveniles' behavior patterns from White, King, and West (2002; i.e., the adults' models in Experiment 1) and from the present study, with illustrations of which group demonstrated significantly more $(+)$, less $(-)$, and equal $(=)$ scores of the measures listed for the period prior to the breeding season (prebreeding) and the breeding season (breeding, including both halves of the breeding season). JA = juvenile-adult condition; juvs = juveniles; hiCS = high countersinging; loCS = low countersinging; $\mathrm{S}=$ social interaction with adults; $\mathrm{O}=$ observe adults; $\mathrm{CS}=$ countersinging; nn males $=$ near neighbor associations with males; cops $=$ copulations; pot $=$ potency; usurps $=$ usurpations; mating $=$ mating patterns $($ monog $=$ monogamous or promis $=$ promiscuous)

daily observations, however, we believed that any simple copying explanation would not suffice to explain the differences across groups. Instead, we hypothesized that small differences in social affiliations and singing patterns that emerged very early in development produced different opportunities for learning (see also White, King, Cole, \& West, 2002). Juveniles were exposed to these different learning environments but also served to create them. Thus, whereas the presence of adults set the early conditions in the groups, the juveniles could then interact with each other differently and could learn from one another differently than could the juveniles in conditions in which adults were not present.

Irrespective of the mechanism of effect, the differences seen in the two groups of juveniles had the potential to be functionally important. Because of differences in variance in mating success, mating patterns, and reproductive output between the groups in the White, King, and West (2002) study, differences in the opportunity for sexual selection existed between groups (see also West, White, \& King, 2002). The purpose of this experiment was to determine whether these differences could remain stable across generations (i.e., if the different patterns could be culturally transmitted). If so, then population differences in behavior could remain intact even without genetic divergence (Boyd \& Richerson, 1985; Gottlieb, 1999; Hochberg, Sinervo, \& Brown, 2003; Jablonka \& Lamb, 2005; Laland, Richerson, \& Boyd, 1996; Mousseau \& Fox, 1998; West \& King, 1987; West-Eberhard, 2003) but could have the potential to drive genetic divergence.

Cowbirds are an excellent model species for studying how different social contexts can structure behavioral development because in the wild cowbirds can experience a wide variety of social environments across their range. Being obligate brood parasites that parasitize a variety of hosts, as well as being nonterritorial dietary generalists, cowbirds can be found across numerous different habitat types (Morrison et al., 1999; Ortega, 1998). Flocks can vary in density, sex ratio, and sex and age-class composition (Friedmann, 1929; O'Loghlen \& Rothstein, 1993, 2003; Ortega, 1998; Woolfenden, Gibbs, \& Sealy, 2001). In addition, across populations and subspecies, cowbirds display dramatic behavioral variation, for example, in song variants, in song and whistle structure (King \& West, 1988; O'Loghlen \& Rothstein, 2003; Rothstein, Yokel, \& Fleischer, 1988), and in mating patterns, which are reported to vary from monogamy to polygamy to promiscuity (Barnard, 1998; Friedmann, 1929; Rothstein, Yokel, \& Fleischer, 1986; Teather \& Robertson, 1986; Yokel \& Rothstein, 1991).

Here we created four learning environments for juvenile males. We varied group composition, giving juveniles access to adult males exhibiting different patterns of competitive, courtship, and vocal behavior. Our goal was to determine whether patterns of social behavior could be transmitted to a new generation and, if so, under what circumstances would such transmission occur. Specifically, we focused on countersinging (CS), a social behavior that convergent lines of evidence have suggested to be critically important for cowbird social development (West et al., 2002; White, King, \& West, 2002). CS, which occurs when males sing to each other in close proximity, has been shown to influence adult male mating success, female reproductive stimulation, and juvenile social development. The clearest difference among the JA and J juveniles from White, King, and West (2002) was in CS. By the breeding season, JA juveniles engaged in CS at levels comparable with the adults with whom they were housed. J juveniles rarely engaged in any CS. Escalated bouts of CS were associated with aggression among the juvenile males housed with adults, which also was associated with mate guarding and with monogamous 
interactions with females. In contrast, low CS among males was associated with higher song quality.

In each of the two experiments reported here, we gave groups of juvenile male cowbirds experience with adult males that engaged in varying levels of CS. We then documented the patterns of CS produced by the juvenile males. In the breeding season, we measured how closely the juvenile males' mating patterns corresponded with the mating patterns of their adult models. Within each experiment, for the second half of the breeding season we allowed the two groups of juvenile males to interact with each other to determine if the differing social experiences during development could produce enduring differences in the juveniles' courtship and communication.

We made a priori predictions that the different patterns of social behavior exhibited by the adult males (see Table 1) would transmit to the new generation of juveniles. Because of the persistent differences we have found in adjacently housed flocks in the past, we hypothesized that social interactions would be necessary for transmission to occur.

\section{Experiment 1: Late Experience}

We gave two groups of juvenile males in adjacent aviaries 72-day access to two groups of adult males. The adult males were the original JA and J males from the White, King, and West (2002) study who had histories of producing either high amounts (JA males) or low amounts ( $\mathrm{J}$ males) of CS. Juveniles interacted with these adults in the late spring, just before the breeding season, a time in nature when birds would be returning to their breeding grounds, competing for access to females, and beginning to court.

\section{Method}

Subjects. Fourteen juvenile male brown-headed cowbirds (Molothrus ater), collected in Monroe County, IN, served as subjects throughout the experiment. In addition, 6 juvenile females, 24 adult females, and 20 adult males were also present in the aviaries. We placed unique combinations of colored leg bands on all birds to permit individual identification. We caught juveniles in the summer of 2001 and adults during the summers of 1999 and 2000. We determined the age of birds on the basis of plumage (Selander \& Giller, 1960). Juveniles were born in the summer of 2001 and thus had never experienced a breeding season. Adult males were trapped as juveniles in 1999 and 2000 and were the original juvenile males from White, King, and West (2002; plus others from replicate flocks). We characterized adult males on the basis of the amount of CS in which they engaged during the 2001 breeding season. We selected the 10 males that engaged in the most CS and the 10 males that engaged in the least CS (for other details of their behavior see White, King, \& West, 2002).

Measures. Four observers recorded social assortment and vocalization patterns for a total of $141.72 \mathrm{hr}$. We began observing at approximately $0700 \mathrm{~h}$ for .75 to $1.0 \mathrm{hr}$ per aviary, 5 days per week prior to the breeding season (February 15-May 3), and $3.0 \mathrm{hr}$ per aviary, 7 days per week during the breeding season (May 4-June 21). Observers rotated through both conditions each day. We recorded data with speech recognition software (see White, King, \& Duncan, 2002).

For song censuses, we collected data in 15-min blocks in which we recorded male vocalization patterns by using ad lib sampling
(Altmann, 1974) based on procedures we had used in the past (see White, King, \& West, 2002). For each vocalization, we recorded whether it was directed or undirected. We recorded directed vocalizations when males whistled or sang to another bird, oriented between 0 and 45 degrees to the recipient and located no more than $60 \mathrm{~cm}$ away. We recorded all other vocalizations as undirected. We used programmable databases (4th Dimension 6.5.1, ACI, Inc., 2001) to assess, for each directed vocalization, whether it was part of a CS bout. For a directed song to be considered in a CS bout, we had to observe two birds sing at least one directed song each to each other with no more than 15 s elapsing between songs. During observations, we also noted when birds ended social interactions by flying away. We scored a departure if a bird flew or moved out of range of a directed song within $1 \mathrm{~s}$ of either singing or receiving the song. Higher numbers of departures decrease the opportunities for extended bouts of CS. We also recorded a variety of other behaviors. As a measure of aggression, we noted all fights that occurred. In the breeding season, we recorded all copulations. We also scored usurpations, defined as a male copulating with a female who went into a posture as a result of another male's directed song (for more details of behavioral measures, see White, King, \& West, 2002).

Because CS occurs only in high frequencies near the breeding season, we also measured near neighbor associations. We have used near neighbor associations in the past to provide a measure of the overall amount of social behavior occurring in groups Amounts of near neighbor associations among males have correlated positively with the amounts of CS produced (West et al., 2002; White, King, \& West, 2002), as the more associations individuals have, the more opportunities exist for singing interactions. In 7-min blocks, we sampled birds in each aviary and recorded any other bird within approximately $30 \mathrm{~cm}$ of the target individual. Any recorded pair would not be recorded as another near neighbor association again unless they moved apart and reassociated. During the near neighbor blocks, we also recorded any copulations, usurpations, and fights that occurred.

Procedure. From July 2001 until February 2002, we housed all birds in same-sex groups in four aviaries. We housed in separate aviaries the two groups of adult males that came from the different CS conditions. Aviaries were large $(9.1 \mathrm{~m} \times 21.4 \mathrm{~m} \times$ $3.4 \mathrm{~m}$ ) outdoor enclosures. All contained small trees, shrubs, grass, perches, a feeding station, and access to an indoor shelter. We fed them a modified Bronx zoo diet for blackbirds mixed with white and red millet and canary seed, and we provided them daily with vitamin-fortified water.

On February 1, 2002, we separated the 14 juvenile males, randomly assigning them to two equally sized groups. We housed them in adjacent aviaries that were separated only by hardware cloth. We referred to the two conditions on the basis of the type of adult males that were to be introduced. The aviary that would house adult males that engaged in high levels of CS was referred to as the high CS (hiCS) condition, and the aviary that would house adult males that engaged in low levels of CS was referred to as the low CS (loCS) condition.

On February 15, we added 7 adult males to the two conditions. On March 7, we randomly assigned 12 adult females and 3 juvenile females to each condition. On March 15, we replaced 3 adult males from each condition that did not sing at all during the previous month with adult males that had appropriate high or low 
CS histories. On April 19, we switched females between the two conditions. We switched females as a control because we had evidence from past work that individual females can create and maintain differences in juvenile male competition (see King, White, \& West, 2003).

We removed adult males from the aviaries on April 28. At this time, we also removed the juvenile females from each aviary before the breeding season began and replaced them with 3 wildcaught females. The juvenile females were needed for a series of playback experiments. During the breeding season, we collected 40 near neighbor blocks and 90 blocks of song censuses per aviary.

For the second half of the breeding season (June 7-21), we removed a $60 \mathrm{~cm} \times 180 \mathrm{~cm}$ barrier separating the two aviaries, allowing all birds in the two conditions to interact. We collected 23 blocks of near neighbor associations and 46 blocks of song censuses for the combined group.

Song recordings and playbacks. We recorded juvenile male vocalizations in the aviaries during the 1st week of May and again during the last week of June by using Sennheiser RF condenser microphones (Sennheiser Electronic Corporation, Old Lyme, CT) recorded into a Sony TCD-D10 PRO digital audiotape recorder. We recorded a sample of approximately 30 songs per male in each of the two recording sessions. We selected one song from each juvenile male on the basis of song quality to use in a playback experiment. We dubbed the breeding season recordings onto an Otari MX III half-track (Otari USA, Chatsworth, CA) recorded at $36 \mathrm{~cm} / \mathrm{s}$. We played back songs with an Otari half-track recorder, a Urei 537 1/3-octave equalizer (Urei, Inc., Northridge, CA) and a Crown D75 power amplifier (Crown International, Elkhart, IN) through JBL 2105 speakers (JBL Inc., Woodbury, NY) located in sound-attenuating chambers. The sound pressure levels of the songs were $85 \pm 2 \mathrm{~dB}$ (a weighted impulse reading at $.8 \mathrm{~m}$ from the speaker as recorded by a B\&K 2209 sound pressure meter; B\&K Components Ltd., Buffalo, NY).

Starting on May 15, 2002, we played the songs to a group of 12 females housed in sound-attenuating chambers and measured each song's effectiveness at eliciting a copulatory response. Six of the females were adults, which were wild caught in February 2002. Because of a shortage of females, we used the 6 juvenile females from the hiCS and loCS conditions as playback subjects. On April 27,2002 , we brought females into the $1.3-\mathrm{m}^{3}$ chambers and housed them either singly or in pairs (for more details see Smith, King, \& West, 2000; West, King, \& Freeberg, 1996a, 1996b).

We played six songs per day to females. Each song trial was separated by $90 \mathrm{~min}$. We counterbalanced the order in which we played back songs, with each presented six times over the course of the experiment. We scored a positive response if the female presented a copulatory solicitation display (posture) within $1 \mathrm{~s}$ of the onset of the song. To calculate song potency, we computed mean responses per female for each song and averaged over all males in each condition. The juvenile females from the hiCS and loCS conditions responded in similar patterns to the other females in the playback experiments, thus we combined their data.

Because of low numbers of subjects and heterogeneity of variance, we used nonparametric statistics throughout. We report medians and semi-interquartile ranges for descriptive purposes. All tests were two-tailed. We had a priori predictions that significant differences across conditions in the behavior of the juveniles would be the same differences as those found between the condi- tions of the adult models from White, King, \& West (2002) listed in Table 1. Because of these predictions, we conducted a limited selection of comparisons between groups and did not correct for multiple comparisons (Howell, 2002). Two juvenile males from the hiCS condition died during the course of the experiment. Their data were removed from subsequent analyses.

\section{Results}

Figure 1 depicts patterns of near neighbor associations with males, and Figure 2 depicts amount of CS produced for (a) adult males and (b) juvenile males for the different phases of the experiment. Summing across the entire experiment (for all phases after the introduction of adult males), hiCS juvenile males engaged in significantly more CS than did loCS juvenile males (hiCS $M d n=788 \pm 142.5$ CS songs per male; loCS $M d n=295 \pm 139.5$ CS songs per male), $U(5,7)=2, p<.05$. Results for the different phases of the experiment are described below to detail the development of the two groups of juveniles.

Prior to the breeding season. Adult males engaged in near neighbor associations and CS as predicted by their developmental histories. HiCS adult males had more near neighbor associations
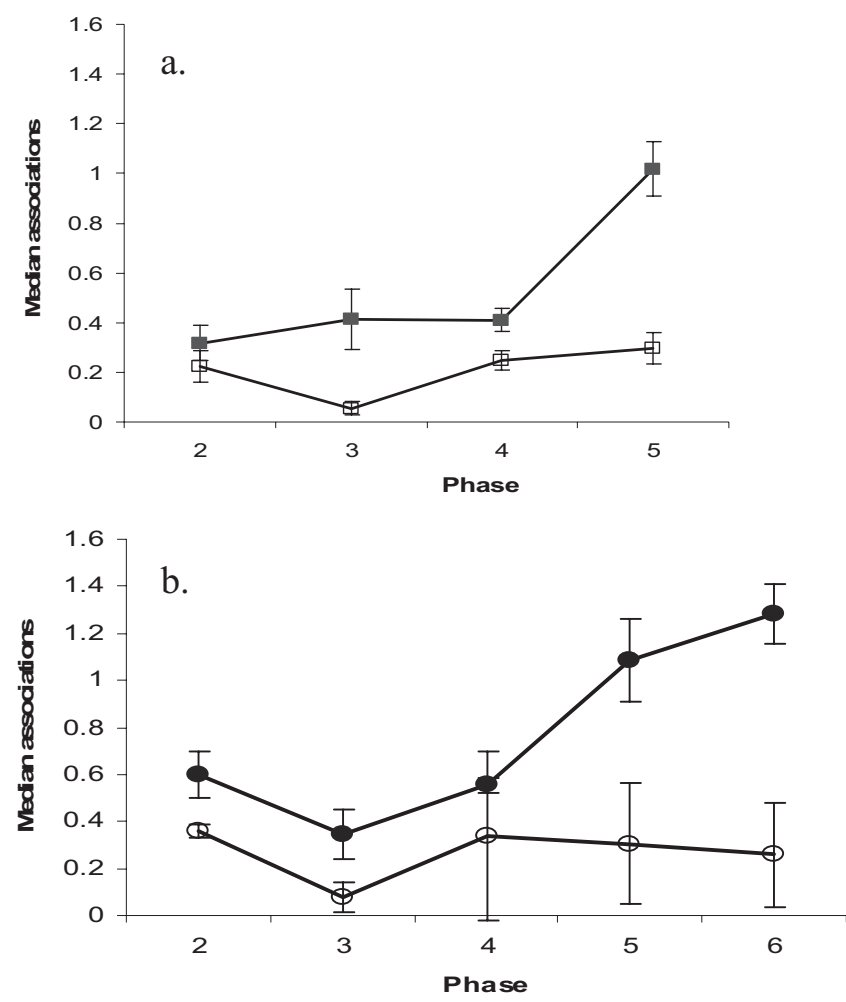

Figure 1. Mdn ( \pm semi-interquartile range) near neighbor associations with males per male per block for (a) adult males and (b) juvenile males in the high countersinging (solid symbols) and the low countersinging (open symbols) conditions in Experiment 1 . Phase $1=$ prior to adult male introduction; Phase 2 = after male but prior to female introduction; Phase 3 = after female introduction; Phase $4=$ replacement of adult males; Phase $5=$ reversal of females; Phase $6=$ breeding season (removal of adult males); Phase $7=$ opening of aviaries. 

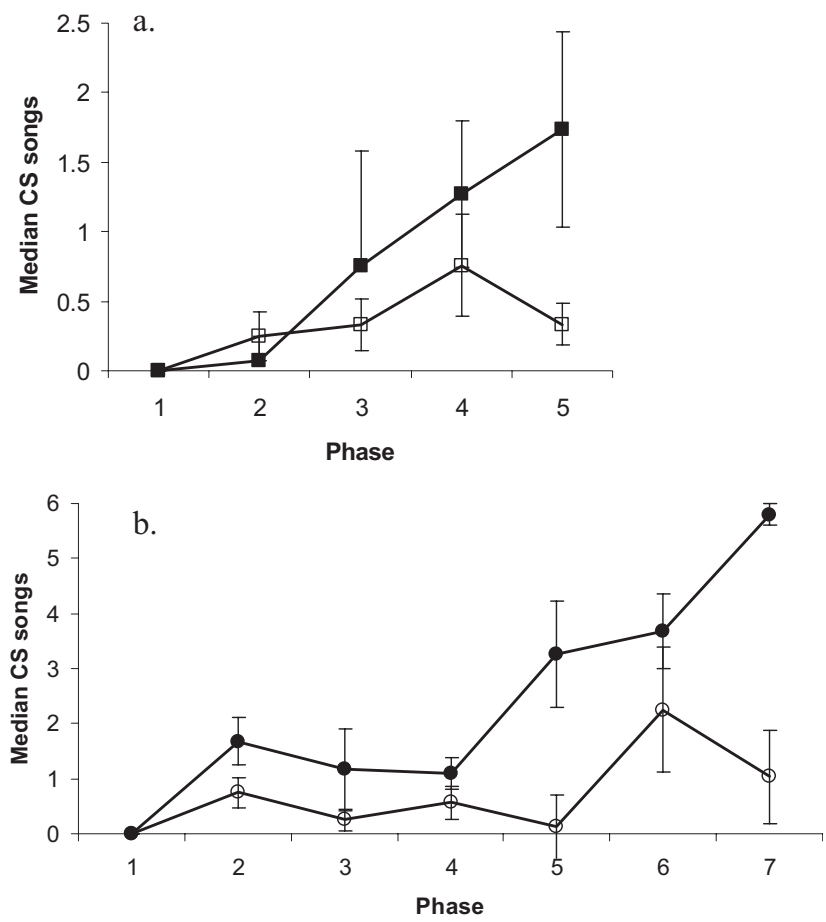

Figure 2. $M d n$ ( \pm semi-interquartile range) countersinging (CS) songs per male per block for (a) adult males and (b) juvenile males in the high CS (solid symbols) and the low CS (open symbols) conditions in Experiment 1. Phase $1=$ prior to adult male introduction; Phase $2=$ after male but prior to female introduction; Phase $3=$ after female introduction; Phase $4=$ replacement of adult males; Phase $5=$ reversal of females; Phase $6=$ breeding season (removal of adult males); Phase $7=$ opening of aviaries.

and CS than did loCS adult males, but only when females were present (Phases 3-5, Figures 1 and 2).

Juvenile males in the two conditions did not differ before adult males were introduced. By the time the adults were removed prior to the breeding season, however, juvenile males in the hiCS condition engaged in more near neighbor and more CS interactions, both $U \mathrm{~s}(5,7)=0$, both $p \mathrm{~s}<.005$, than did the juvenile males in the loCS condition (Phases 2-5, Figures 1 and 2).

Breeding season. After the removal of the adult males, juvenile males in the hiCS condition had significantly more near neighbor associations with other males, $U(5,7)=0, p<.005$; and with females, $U(5,7)=0, p<.005$, than did the loCS juvenile males. The hiCS juvenile males engaged in more CS, but because 1 male rarely sang at all, the difference did not reach significance, $U(5,7)=7, n s$. The loCS juvenile males departed more often when sung to than did the hiCS juveniles (as a proportion of directed song sung, $M d n$ departures for hiCS juveniles: .11 \pm .03 ; loCS juveniles $=.21 \pm .02), U(5,7)=3, p<.05$. Males in the hiCS condition showed more fidelity in singing to individual females; $95.5 \%$ ( $\pm .017 \%$ ) of songs directed to females in the hiCS condition came from the female's consort male (the male who sang the majority of songs to the female) compared with $72.5 \%$ $( \pm .04 \%)$ of songs directed to females from the consort male in the loCS condition, $U(10,10)=5.5, p<.001$. Other patterns of mating behavior displayed by the juvenile males were similar to the patterns their adult male models displayed in their first breeding season (see Table 1), including significantly more fights in the hiCS condition, $U(5,7)=3, p<.05$, more usurpations in the loCS condition, $U(5,7)=5, p<.05$, and females mating with significantly more partners in the loCS condition $(M d n$ partners per female who copulated: hiCS females, $1.0 \pm .0$; loCS females, $2.0 \pm .22), U(9,7)=4.5, p<.005$.

Aviaries opened. When the divider between the two aviaries was removed, juvenile males maintained their different behavior patterns; in fact, the differences were more pronounced. In addition, juveniles assorted and interacted predominantly with birds from their initial condition. Table 2 provides raw data of male singing patterns.

HiCS juvenile males had significantly more near neighbor associations with males than did the loCS juvenile males $(U=1$, $p<.01)$. Compared with the loCS males, the hiCS males engaged in more CS $(U=0, p<.005)$. Both groups associated more with birds from their conditions. Of male-male near neighbor associa-

Table 2

Song Patterns for Individual Males After Conditions Were Merged (Experiment 1)

\begin{tabular}{|c|c|c|c|c|c|c|}
\hline $\begin{array}{l}\text { Subject's } \\
\text { acronym }\end{array}$ & Dir F & $\mathrm{CS}$ & $\mathrm{P}$ dir hiCS F & P CS hiCS & Fights & Cops \\
\hline \multicolumn{7}{|l|}{$\mathrm{HiCS}$} \\
\hline MMYL & 3.87 & 7.46 & .983 & .956 & 10 & 1 \\
\hline MNOB & 10.82 & 5.93 & .996 & .945 & 8 & 12 \\
\hline MORN & .64 & 3.43 & .5 & .886 & 11 & 0 \\
\hline MWOR & 6.5 & 5.80 & .134 & .592 & 14 & 4 \\
\hline MYMB & 8.78 & 5.54 & 1 & .973 & 1 & 4 \\
\hline \multicolumn{7}{|l|}{ LoCS } \\
\hline MBOR & 1.09 & 2.87 & .1 & .455 & 6 & 1 \\
\hline MBOY & .5 & .61 & .391 & .107 & 0 & 0 \\
\hline MGRL & 2.46 & 1.04 & .053 & .396 & 1 & 3 \\
\hline MOYW & 6.07 & 2.30 & .703 & .255 & 6 & 1 \\
\hline
\end{tabular}

Note. First column lists leg band acronyms for each juvenile male in the hiCS (high countersinging) and loCS (low countersinging) conditions. Dir F $=$ total directed songs to females per song block; $\mathrm{CS}=$ total songs sung in CS bouts per song block; P dir hiCS F = proportion of female-directed songs sung to hiCS females; P CS hiCS $=$ proportion of CS songs sung with hiCS males; fights $=$ total number of fights recorded; cops $=$ total number of copulations. 
tions for hiCS males, $86.8 \%$ ( $\pm .03 \%$ ) were with other hiCS males $(T=0, p<.05)$, and of loCS male-male near neighbor associations, $69.2 \%( \pm .06 \%)$ were with loCS males $(T=0, p<.05)$. Female associations followed the same pattern, with loCS condition females having $72 \%( \pm .03 \%)$ of their female associations with other loCS females $(T=0, p<.005)$. Females from the hiCS condition allocated $68.0 \%( \pm .11 \%)$ of their female near neighbor associations to hiCS females $(T=3.5, p<.05)$. Females from the initial hiCS condition had $88.7 \%( \pm 5.67 \%)$ of their male near neighbor associations with males from their home condition $(T=$ $0, p<.01)$. Females from the initial loCS had $78.8 \%( \pm 7.12 \%)$ of their male near neighbor associations with males from their home condition $(T=10, p=.074 ; 9$ of the 10 loCS females spent more time with males from the loCS condition).

Singing interactions were also organized by initial condition. HiCS males sang $87 \%$ of their CS songs with other hiCS males ( $T=0, p<.05)$. LoCS males sang $78 \%$ of their CS songs with loCS males $(T=1, p<.05)$. In both groups, males sang preferentially to females from their home conditions (loCS, $79.0 \%$ of female-directed songs to loCS females, $T=2, p<.05$; hiCS, $72 \%$ of female-directed songs to hiCS females, $T=2, n s$ ).

All copulations that occurred when the aviaries were open were between birds that had been in the same original condition, except for one between a hiCS male (which was given the acronym MWOR) and a loCS female. In this case, the female had not copulated with any other male in the breeding season and may have established a consort with MWOR early, prior to the female switch. The three usurpations that occurred during Phase 7 were all among birds in the loCS condition.

Results of the playback analysis revealed that the songs from males in the loCS condition were significantly more effective at eliciting females' copulatory postures ( $M d n$ proportion of total playbacks for each song to which females responded with a copulatory posture (loCS condition $=.47 \pm .11$; hiCS condition $=$ $.21 \pm .125 ; T=3, p<.05)$.

\section{Discussion}

Juvenile males took on the behavioral profiles of adult males with whom they had interacted. Juveniles produced breeding behaviors similar to the adults even though the adults had been removed by the breeding season, thus not providing juveniles the opportunity to observe directly their breeding behavior (e.g., copulations, fights, usurpations, mate guarding). This suggested that the transmission of behavior patterns from adults to juveniles was not based on copying or imitation of these final behaviors. Patterns of CS were similar between adults and juveniles within condition, thus it is possible that the juveniles copied CS behavior. The two groups of juveniles diverged even though they were always in visual and acoustic contact. Thus social interactions were critical for transmission.

\section{Experiment 2: Early Experience}

Experiment 1 suggested that interactions with adults were setting juveniles on different developmental trajectories, and these different trajectories were allowing the juveniles to reconstruct the behavior patterns of the adults. In Experiment 2, we again gave juvenile males adult male exposure, but here we provided the social experience earlier in the year. We exposed juvenile males to adults in the fall when adult males are engaging in very little singing activity, in almost no CS, and in no courtship. Could juvenile males be placed onto different developmental trajectories that would lead to competitive courtship behavior from a brief interaction with adult males early in the fall? We also designed this experiment to test the importance of being able to interact with the adult males as opposed merely to observe them. We therefore gave one group of juvenile males social access to a group of competitive adult cowbirds, and we housed a second group of juvenile males in an aviary adjacent to this large flock. Thus this second group could see and hear the first group interact with the adults; the only difference in experiences for the two groups of juveniles was whether they could interact with the adults.

\section{Method}

Subjects. Fourteen wild-caught juvenile males served as subjects in this experiment. We caught juveniles in Monroe County, IN, in the summer of 2002. We placed colored leg bands on them and housed them in aviaries of the same dimensions as in Experiment 1 .

Procedure. We randomly assigned juvenile males to two groups. On October 16, 2002, we housed one group of the juveniles (social interactions with adults $=S$ ) in a large $(9.1 \mathrm{~m} \times$ $64.2 \mathrm{~m} \times 3.4 \mathrm{~m}$ ) aviary that also contained a flock of 28 adult male and 32 adult female cowbirds. We housed the second group of juvenile males (observe adults $=\mathrm{O}$ ) adjacent to the large flock in a $9.1 \mathrm{~m} \times 21.4 \mathrm{~m} \times 3.4 \mathrm{~m}$ aviary, thus the $\mathrm{O}$ juveniles could see and hear the large flock but could not interact socially with the birds within it. We observed these groups and collected data with the techniques outlined in Experiment 1 . We collected 20 song and 20 near neighbor blocks in each of the two groups from October 16 to November 7.

On November 7, we removed the $\mathrm{S}$ juveniles from the large flock, and we placed both groups of juveniles in new adjacent aviaries, each with 10 unfamiliar females and no adult males. We then observed the groups through the winter, spring, and breeding seasons. Similar to Experiment 1, we switched the females from the two conditions in the spring to control for any differences in the behavior of the juvenile males resulting from female behavior (King et al., 2003). We observed the two groups and recorded behavior by using the same procedures as in Experiment 1. We collected 43 song and 29 near neighbor blocks in the period prior to the breeding season (February 2-April 30). We collected 75 song and 29 near neighbor blocks in the breeding season (May 1-June 1). We then removed the divider separating the two aviaries for the second half of the breeding season and took an additional 64 song blocks and 24 near neighbor blocks (June 2-14). In addition, we made song recordings and conducted playbacks by using the same procedures from Experiment 1. Over the course of the experiment one juvenile male in the $\mathrm{S}$ condition died. We removed his data from all subsequent analyses.

\section{Results}

Overall, summing across the fall, spring, and breeding seasons, $\mathrm{S}$ juveniles and $\mathrm{O}$ juveniles behaved in patterns similar to the patterns of the hiCS and loCS juveniles, respectively (see Figures 
3 and 4). Compared with the $\mathrm{O}$ juveniles, the $\mathrm{S}$ juveniles had more near neighbor associations with other juveniles ( $M d n$ near neighbor associations per juvenile: $S$ juveniles, $286 \pm 46.6$; O juveniles, $186 \pm 36.50), U(6,7)=5, p<.05$; had fewer departures as a proportion of directed song sung $(\mathrm{S}$ juveniles: $.11 \pm .02 ; \mathrm{O}$ juveniles: $.17 \pm .04), U(6,7)=6, p<.05$; and engaged in more CS (Mdn CS songs produced per juvenile: $\mathrm{S}$ juveniles $=503 \pm$ 134.5; O juveniles $=163 \pm 106.25), U(6,7)=6, p<.05$. Songs of $\mathrm{O}$ juveniles were significantly more effective at eliciting copulatory postures than were songs of $\mathrm{S}$ juveniles (mean postures elicited per playback: $\mathrm{O}$ juveniles, $.39 \pm .08$; $\mathrm{S}$ juveniles, $.34 \pm$ .08 ), Wilcoxon $T(16)=18, p<.01$. Results for the different phases of the experiment are described below to detail the development of the juveniles.

The large flock. There was very little CS produced by any of the birds in the fall (S juveniles: $.067 \pm .04 \mathrm{CS}$ songs per block; O juveniles: $.057 \pm .03 \mathrm{CS}$ songs per block; $\mathrm{S}$ adults: $.11 \pm .05 \mathrm{CS}$ songs per block). There were no significant differences in any singing patterns between the two groups of juveniles. Within the large flock, $\mathrm{S}$ juveniles directed $81.1 \%( \pm .05 \%)$ of their maledirected songs to adult males. Adult males directed $82.6 \%$ $( \pm .07 \%)$ of their male-directed songs to other adults. S juvenile males had significantly more near neighbor associations with other males than did the $\mathrm{O}$ juveniles ( $\mathrm{S}$ juveniles $M d n=50.5 \pm 8.5$; $\mathrm{O}$ juveniles $M d n=23 \pm 4.0), U(6,7)=0, p<.001$. Within the large flock, $\mathrm{S}$ juveniles had $67.48 \%( \pm 3.8 \%)$ of their associations with adult males, $14.5 \%( \pm 3.72 \%)$ with juvenile males, and $15.57 \%( \pm 3.5 \%)$ with females. Adult males had $62.3 \%( \pm 4.6 \%)$ of their associations with other adult males, $12.64 \%$ ( $\pm 5.8 \%)$ with juvenile males, and $20.69 \%$ ( $\pm 9.3 \%$ ) with females.

There was a trend for the two groups of juvenile males to differ in their response to directed songs. $\mathrm{S}$ juveniles departed from a directed song less often than did $\mathrm{O}$ juveniles (as a proportion of number of directed songs sung: $\mathrm{S}$ juveniles $M d n$ departure, $0.0 \pm$ .03 ; O juvenile departures, $.30 \pm .20), U(6,6)=6, p=.05 . \mathrm{S}$ adults rarely ever left during singing interactions with juveniles. There was only one recorded event in which an adult departed to a juvenile song.

Prior to the breeding season. During February 2-April 20, at this point, CS began to emerge in the two groups but did not differ

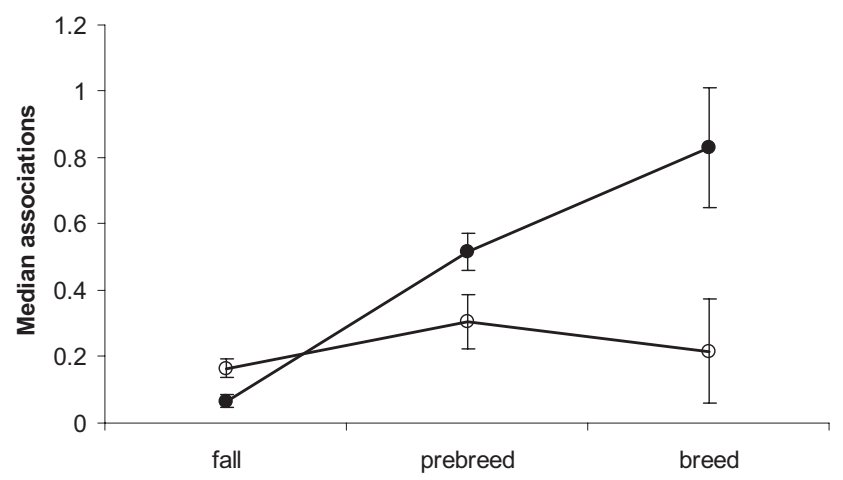

Figure 3. $M d n$ ( \pm semi-interquartile range) near neighbor associations per male per block for juvenile males in the social interaction with adults condition (solid symbols) and observe adults condition (open symbols) in Experiment 2 for data collection sessions in the fall, prebreeding season, and breeding season.

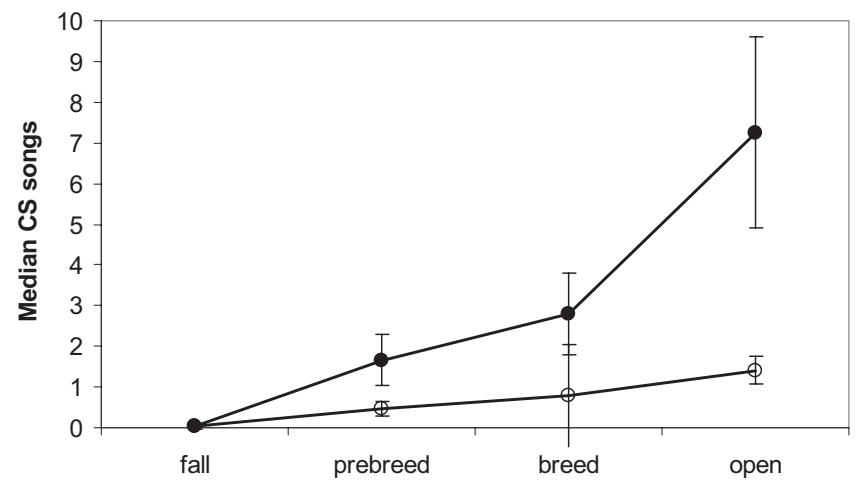

Figure 4. $M d n$ ( \pm semi-interquartile range) countersinging (CS) songs per male per block for juvenile males in the social interaction with adults condition (solid symbols) and observe adults condition (open symbols) in Experiment 2 for data collection sessions in the fall, prebreeding season, breeding season, and when the aviaries were opened.

significantly (S juveniles $M d n=1.66 \pm .62 \mathrm{CS}$ songs per block; $\mathrm{O}$ juveniles $M d n=.47 \pm .18 \mathrm{CS}$ songs per block), $U(6,7)=11.5$, $n s$. S juveniles had significantly more near neighbor associations both with males ( $\mathrm{S}$ juveniles $M d n=3.09 \pm .34$ associations per block; O juveniles $M d n=2.14 \pm .57$ associations per block), $U(6$, $7)=2, p<.005$; and with females ( $\mathrm{S}$ juveniles $M d n=1.52 \pm .09$ associations per block; $\mathrm{O}$ juveniles $M d n=.31 \pm .15$ associations per block), $U(6,7)=1, p<.002$, than did $\mathrm{O}$ juveniles. O juveniles had significantly more departures as a proportion of directed song $(.25 \pm .05)$ than did $\mathrm{S}$ juveniles $(.14 \pm .02), U(7,6)=5, p<.05$.

Breeding season. In the breeding season, CS did not differ significantly between the two conditions (S juveniles: $2.8 \pm 1.0$ CS songs; O juveniles: $.8 \pm 1.3 \mathrm{CS}$ songs), $U(6,7)=13$, ns. S juveniles had significantly more near neighbor associations with males than did $\mathrm{O}$ juveniles $(144.5 \pm 31.38$ vs. $44 \pm 32.0$ near neighbor associations for $\mathrm{S}$ and $\mathrm{O}$ juveniles, respectively), $U(6$, $7)=3, p<.01$; but not females $(26 \pm 22.3$ vs. $20 \pm 23.0$ near neighbor associations for $\mathrm{S}$ and $\mathrm{O}$ juveniles, respectively), $U(6$, $7)=17, n s$. Juveniles from the two groups no longer differed on the basis of departures by the breeding season (.14 $\pm .01 \mathrm{vs} .15 \pm$ .05 departures per directed song per male for $\mathrm{S}$ and $\mathrm{O}$ juveniles, respectively), $U(6,7)=18, n s$. The groups did not differ significantly in their number of copulations $(1.0 \pm 1.5$ vs. $1.0 \pm 3.5$ copulations per male for $\mathrm{S}$ and $\mathrm{O}$ juveniles, respectively), $U(6$, $7)=19.5, n s$. There were no differences in fights (4.0 $\pm 1.0 \mathrm{vs}$. $5.0 \pm 2.2$ fights per male for $\mathrm{S}$ and $\mathrm{O}$ juveniles, respectively), $U(6,7)=19.5, n s$. We did not observe any usurpations in Experiment 2.

Aviaries opened. Although we found few pronounced differences between the two groups of juveniles in the first half of the breeding season, once we opened the aviaries and allowed the two groups to interact, differences became clear. Table 3 lists detailed measures for individual males. Compared with $\mathrm{O}$ juveniles, $\mathrm{S}$ juveniles sang significantly more CS, $U(6,7)=2.5, p<.01$; had more fights, $U(6,7)=5, p<.05$; and had fewer departures, $U(6$, $7)=0, p<.001$. Similar to Experiment 1 , singing was organized by initial condition. 
Table 3

Song Patterns for Individual Males After Conditions Were Merged (Experiment 2)

\begin{tabular}{|c|c|c|c|c|c|c|}
\hline $\begin{array}{l}\text { Subject's } \\
\text { acronym }\end{array}$ & Dir $\mathrm{f}$ & $\mathrm{CS}$ & $\mathrm{P} \operatorname{dir} \mathrm{S} F$ & P CS S & Fights & Cops \\
\hline \multicolumn{7}{|l|}{$\mathrm{S}$ juveniles } \\
\hline MDRW & .66 & 4.17 & .909 & .993 & 4 & 0 \\
\hline MG2M & 4.88 & 3.56 & .929 & .934 & 3 & 8 \\
\hline MGLY & 2.7 & 1.08 & .963 & 1.000 & 4 & 2 \\
\hline MLWM & 2.78 & 3.69 & .988 & .894 & 1 & 1 \\
\hline MO2Y & 2.28 & 4.83 & .373 & .964 & 9 & 1 \\
\hline MWOL & .34 & .75 & .474 & .750 & 4 & 0 \\
\hline \multicolumn{7}{|l|}{ O juveniles } \\
\hline MDGL & .11 & .19 & .250 & .250 & 0 & 0 \\
\hline MDRD & .31 & 1.30 & .286 & .120 & 2 & 0 \\
\hline MDYL & 2.77 & .61 & .037 & .128 & 3 & 11 \\
\hline MG2W & .81 & .72 & .704 & .304 & 3 & 0 \\
\hline MGWN & .53 & .00 & .467 & - & 0 & 0 \\
\hline MGWR & 1.17 & .75 & .041 & .188 & 0 & 0 \\
\hline MNYW & 2.61 & .70 & .031 & .178 & 2 & 0 \\
\hline
\end{tabular}

Note. First column lists band acronyms for each juvenile male in the $\mathrm{S}$ (social interaction with adults) and $\mathrm{O}$ (observe adults) conditions. Dir F = directed songs to females per song block; $\mathrm{CS}=$ total songs sung in CS bouts per song block; P dir S F = proportion of female-directed songs sung to S females; P CS S = proportion of CS songs sung with $\mathrm{S}$ males; fights = total number of fights recorded; cops = total number of copulations. The dash indicates that the male did not countersing.

\section{Discussion}

Juvenile males produced patterns of courtship and communication similar to those of the adult males with whom they had interacted. In Experiment 1, juvenile males housed either with competitive or noncompetitive adult males prior to the breeding season exhibited similar patterns of male competition and breeding behaviors as the adults did in their 1st year. In Experiment 2, only juvenile males who had social experience with competitive adults in the fall developed competitive courtship patterns by the breeding season.

The form of social influence on behavior depicted here differs from traditional concepts of cultural transmission of bird song in which a behavior pattern is directly copied. Here, juveniles never even had the opportunity to observe the breeding behaviors of the adults that they came to replicate. Instead, adults' behaviors (or lack thereof) set the early conditions for the groups' patterns of social engagement (see also White, King, Cole, \& West, 2002). Social experience with competitive adults led juveniles to interact more often. With these conditions set, juveniles were exposed to different learning environments in which different types of information were available and different contingencies connected to their behavior existed. For example, in Experiment 2, early in the fall $\mathrm{S}$ juveniles sang to adult males. Adult males rarely ever departed in response to the juveniles' song. After the exposure to the adults in the large flock, the first significant difference between the two groups of juveniles was in departures. S juveniles learned to respond to song by staying, whereas $\mathrm{O}$ juveniles were more likely to depart and thus rarely could observe the consequences of singing. In effect, $\mathrm{O}$ juveniles constructed a condition of selfimposed social isolation. They rarely engaged in social interactions, rarely competed with song with other males, and in turn developed higher potency song, which is a characteristic of males developing in experimentally imposed male social isolation (West \& King, 1980).
Although juveniles may not have imitated the adults, they were nevertheless cultured in the different environments. The new generations constructed anew the culture of the past generation. Social influences on behavior can be diverse and need not be restricted to situations in which a naive observer learns by observing, copying, or imitating a knowledgeable conspecific. Galef (1995) suggested that social learning should be considered socially biased individual learning. This description is particularly appropriate here. In these experiments, no matter how the juveniles learned, what they learned differed depending on the social group they experienced (see also Coussi-Korbel \& Fragazy, 1995).

In both experiments, the differences between the groups became more pronounced when the two aviaries were opened and all birds could interact. At this point, we cannot determine whether the assortment was due to the different behavioral profiles of the birds or due to their familiarity within their group. Either possibility is important as both suggest that the differences in behavior could be maintained when all physical barriers were removed and only social ones remained. The persistence of the behavioral differences was surprising because one of the main characteristics of juvenile males in their 1st year is that they can rapidly reorganize their behavior in response to a change in the social environment (King et al., 2003). We kept the two groups in constant acoustic and visual contact with one another to simulate a situation in which juveniles within a large group might be exposed to different social experiences within subgroups. Such subgroups have been found to emerge naturally in large captive flocks (Smith, King, \& West, 2002). If social influences on behavior can play a role in group divergence, the immediate group or subgroup must serve as a filter to increase the salience of information within the local group and decrease salience of information outside of the group (see also White, King, Cole, \& West, 2002).

It is nearly impossible to conduct the number of replicate flocks necessary to remove the problem of pseudoreplication. Individuals 
within a group cannot be considered independent, yet we treated them as such in our analyses. Our purpose, however, was to track in detail how individual juveniles interact, learn, and develop within different social groups. Thus, from whom juveniles learn, whether it be from only one dominant adult male, from a number of adult males, from females, from other juveniles, or from a combination of these, is not currently our research question. Statistics here should be considered descriptive; revealing the properties of the social environment to which the individuals are exposed. What we seek to replicate are the outcomes for juveniles exposed to the different social conditions to determine whether such social influences on development are functionally relevant. The patterns found in this experiment replicate patterns from the adult conditions in the prior years. We have replicated several times (seven groups, 66 total males) the conditions that produced the adult males with divergent behavioral repertoires from Experiment 1 , and the adult males used in this study came from several of these replicates.

That these two patterns of social behavior do replicate suggests the possibility that they represent two distinct adaptive strategies. One strategy, functioning predominantly for male-male competition, favors CS, aggression, and mate guarding. The second strategy, functioning for female choice, favors a highly effective courtship song. Both of the two strategies can be found to be successful under different situations (White, King, \& West, 2002). At this point, however, it is too early to determine whether these are adaptive alternative strategies or whether the plasticity is a more general product of the developmental system. It is possible, for example, that there are a multitude of different trajectories that can be produced in different social environments (see Freed-Brown, Miller, King, \& West, in press).

Most work on how cultural factors influence behavior has focused on the spread of species-atypical behavior patterns within a population (Boyd \& Richerson, 1985; Galef, 1990; Rendell \& Whitehead, 2001; Whiten et al., 1999). This is done because focusing on species-atypical behavior reduces the likelihood that the behavior of interest may have spread without being learned socially. This approach however can tend to underestimate the importance and ubiquity of social factors controlling, structuring, and maintaining behavior.

Cultural effects are developmental; they have systemic effects throughout an individual's lifetime. The choices, preferences, and responses of that individual at any given moment can be influenced by factors that occurred earlier in life. This research preparation focusing on ontogenetic cultural effects serves to show that the social environment can create and structure species-typical behavior patterns. The most revealing effect in this study is the development of the "normal" (hiCS and S) groups. Developing species-typical competitive behavior did not unfold by default but instead depended on the particular structure of the social group (see also King et al., 2003). That in the wild such behavior is the norm suggests that the social group can potentially be a dependable and reliable structuring ecology for behavioral development, mating systems, and evolution.

\section{References}

ACI, Inc. (2001). 4th Dimension (Version 6.5.1.) [Computer software]. San Jose, CA: Author.
Altmann, J. (1974). Observational study of behaviour: Sampling methods. Behaviour, 49, 227-267.

Animal Behavior Society. (1997). ABS/ASAB guidelines for the treatment of animals in behavioral research and teaching. Retrieved from http:// www.animalbehavior.org/ABS/Handbook/abspolicy99.html treatment

Barnard, P. (1998). Variability in the mating systems of parasitic birds. In S. I. Rothstein \& S. F. Robinson (Eds.), Parasitic birds and their hosts (pp. 339-356). New York: Oxford University Press.

Boyd, R., \& Richerson, P. J. (1985). Culture and the evolutionary process. Chicago: University of Chicago Press.

Champagne, F. A., \& Curley, J. P. (2005). How social experiences influence the brain. Current Opinion in Neurobiology, 15, 704-709.

Coussi-Korbel, S., \& Fragazy, D. M. (1995). On the relation between social dynamics and social learning. Animal Behaviour, 50, 1441-1453.

Denenberg, V. H., \& Rosenberg, K. M. (1967, November 11). Nongenetic transmission of information. Nature, 216, 549-550.

Foster, S. A., \& Endler, J. A. (1999). Geographic variation in behaviour: Perspectives on evolutionary mechanisms. Oxford, England: Oxford University Press.

Francis, D., Diorio, J., Liu, D., \& Meaney, M. J. (1999, November 5). Nongenomic transmission across generations of maternal behavior and stress responses in the rat. Science, 286, 1155-1158.

Freeberg, T. M. (1996). Assortative mating in captive cowbirds is predicted by social experience. Animal Behaviour, 52, 1129-1142.

Freed-Brown, S. G., Miller, J. L., King, A. P., \& West, M. J. (2006). Examining the sources of variation in social behaviour of female cowbirds (Molothrus ater). Behaviour, 143, 1293-1315.

Friedmann, H. (1929). The cowbirds: A study in the biology of social parasitism. Springfield, IL: C. C. Thomas.

Galef, B. G., Jr. (1990). Tradition in animals: Field observations and laboratory analysis. In M. Beckoff \& D. Jamieson (Eds.), Interpretation and explanation in the study of animal behaviour (pp. 74-95). Boulder, CO: Westview Press.

Galef, B. G., Jr. (1995). Why behaviour patterns that animals learn socially are locally adaptive. Animal Behaviour, 49, 1325-1334.

Gottlieb, G. (1999). Probabilistic epigenesis and evolution. Worchester, MA: Clark University Press.

Hochberg, M. E., Sinervo, B., \& Brown, S. P. (2003). Socially mediated speciation. Evolution, 57, 154-158.

Howell, D. C. (2002). Statistical methods for psychology (5th ed.). Pacific Grove, CA: Thomson Learning.

Jablonka, E., \& Lamb, M. J. (2005). Evolution in four dimensions: Genetic, epigenetic, behavioral, and symbolic variation in the history of life. Cambridge, MA: MIT Press.

King, A. P., \& West, M. J. (1988). Searching for the functional origins of cowbird song in eastern brown-headed cowbirds (Molothrus ater ater). Animal Behaviour, 36, 1575-1588.

King, A. P., White, D. J., \& West, M. J. (2003). Female proximity influences male intrasexual competition in cowbirds (Molothrus ater). Animal Behaviour, 66, 817-828.

Laland, K. N., Richerson, P. J., \& Boyd, R. (1996). Developing a theory of animal social learning. In C. M. Heyes \& B. G. Galef, Jr. (Eds.), Social learning in animals: The roots of culture (pp. 129-154). San Diego, CA: Academic Press.

Michel, G. F., \& Moore, C. L. (1999). Developmental psychobiology: An interdisciplinary science. Cambridge, MA: MIT Press.

Morrison, M. L., Hall, L. S., Robinson, S. F., Rothstein, S. I., Hahn, D. C., \& Rich, T. D. (1999). Studies in avian biology: No. 18. Research and management of the brown-headed cowbird in western landscapes: Proceedings of a symposium of Partners in Flight-Research Working Group. Camarillo, CA: Cooper Ornithological Society.

Mousseau, T. A., \& Fox, C. W. (1998). Maternal effects as adaptations. New York: Oxford University Press.

O’Loghlen, A. L., \& Rothstein, S. I. (1993). An extreme example of 
delayed vocal development: Song learning in a population of wild brown-headed cowbirds. Animal Behaviour, 46, 293-304.

O'Loghlen, A. L., \& Rothstein, S. I. (2003). Female preferences for the songs of older males and the maintenance of dialects in brown-headed cowbirds (Molothrus ater). Behavioural Ecology and Sociobiology, 53, 102-109.

Ortega, C. P. (1998). Cowbirds and their hosts. Tucson: University of Arizona Press.

Rendell, L., \& Whitehead, H. (2001). Culture in whales and dolphins. Behavioural and Brain Sciences, 24, 309-382.

Rothstein, S. I., Yokel, D. A., \& Fleischer, R. C. (1986). Social dominance, mating, and spacing systems, female fecundity and vocal dialects in captive and free-ranging brown-headed cowbirds. Current Ornithology, $3,127-185$

Rothstein, S. I., Yokel, D. A., \& Fleischer, R. C. (1988). The agonistic and sexual functions of vocalizations of male brown-headed cowbirds (Molothrus ater). Animal Behaviour, 36, 73-86.

Schlichting, C. D., \& Smith, H. (2002). Phenotypic plasticity: Linking molecular mechanisms with evolutionary outcomes. Evolutionary Ecology, 16, 189-211.

Selander, R. K., \& Giller, D. (1960). First year plumages of the brownheaded cowbird and red-winged blackbird. Condor, 62, 202-214.

Smith, V. A., King, A. P., \& West, M. J. (2000). A role of her own: Female cowbird influences on vocal development. Animal Behaviour, 60, 599609

Smith, V. A., King, A. P., \& West, M. J. (2002). The context of social learning in brown headed cowbirds: Association patterns in a captive flock. Animal Behaviour, 63, 23-35.

Teather, K. L., \& Robertson, R. J. (1986). Pair bonds and factors influencing the diversity of mating systems in brown-headed cowbirds. Condor, 88, 63-69.

West, M. J., \& King, A. P. (1980). Enriching cowbird song potency by social deprivation. Journal of Comparative and Physiological Psychology, 94, 263-270.

West, M. J., \& King, A. P. (1987). Settling nature and nurture into an ontogenetic niche. Developmental Psychobiology, 20, 549-562.
West, M. J., King, A. P., \& Freeberg, T. M. (1996a). The nature and nurture of neophenotypes. In L. A. Real (Ed.), Behavioral mechanisms in evolutionary ecology (pp. 219-237). Chicago, IL: University of Chicago Press.

West, M. J., King, A. P., \& Freeberg, T. M. (1996b). Social malleability in cowbirds: New measures reveal new evidence of plasticity in the Eastern subspecies (Molothrus ater ater). Journal of Comparative Psychology, $110,15-26$

West, M. J., King, A. P., \& White, D. J. (2003). The case for developmental ecology. Animal Behaviour, 66, 617-622.

West, M. J., White, D. J., \& King, A. P. (2002). Female brown-headed cowbirds' (Molothrus ater) organization and behaviour reflects male social dynamics. Animal Behaviour, 64, 377-385.

West-Eberhard, M. J. (2003). Developmental plasticity and evolution. Oxford, England: Oxford University Press.

White, D. J., King, A. P., Cole, A., \& West, M. J. (2002). Opening the social gateway: Early vocal and social sensitivities in brown-headed cowbirds (Molothrus ater). Ethology, 108, 23-37.

White, D. J., King, A. P., \& Duncan, S. D. (2002). Voice recognition technology as a tool for behaviour research. Behaviour Research Methods, Instruments and Computers, 34, 1-5.

White, D. J., King, A. P., \& West, M. J. (2002). Facultative development of courtship and communication skills in juvenile male cowbirds, $\mathrm{Mo}$ lothrus ater. Behavioural Ecology, 23, 487-496.

Whiten, A., Goodall, J., McGrew, W. C., Nishida, T., Reynolds, V., Sugiyama, Y., et al. (1999, June 17). Cultures in chimpanzees. Nature, 399, 682-685.

Woolfenden, B. E., Gibbs, H. L., \& Sealy, S. G. (2001). Demography of brown-headed cowbirds at Delta marsh, Manitoba. Auk, 118, 156-166.

Yokel, D. A., \& Rothstein, S. I. (1991). The basis for female choice in an avian brood parasite. Behavioral Ecology and Sociobiology, 29, 39-45.

Received February 9, 2006

Revision received November 13, 2006

Accepted November 20, 2006 